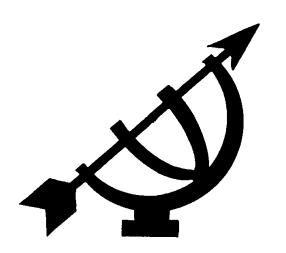

\title{
Kontekstualisering: geologiese tydskaal en preservering van die fossielrekord
}

\author{
M.S. Coetzee
}

Skool vir Omgewingswetenskappe \& Ontwikkeling

Potchefstroomkampus

Noordwes-Universiteit

POTCHEFSTROOM

E-pos: plbmsc@puk.ac.za

F.B. Waanders

Skool vir Chemiese \& Mineraalingenieurswese

Potchefstroomkampus

Noordwes-Universiteit

POTCHEFSTROOM

E-pos: chifbw@puk.ac.za

\begin{abstract}
Contextualising: geological time scale and preserving of the fossil record

Our point of departure is that the universe came into existence 13000 million years ago as a result of a big bang. The earth formed in the known galactic system 4600 million years ago. The concept of geological time and its measurement changed during the course of the history of man. In the 18th century, some natural scientists formed the view that the earth was very old, although it was not possible to determine the absolute age of the earth before the discovery of radioactivity (1896) and its application in the dating of rocks (1905). The principle of uniformity (the present is the key to the past) of James Hutton (1726-1797) is replaced in modern geology with the constancy of natural laws and uniform processes, while acknowledging that the rates of processes may vary considerably. It is also acknowledged that natural catastrophic occurrences, like meteorite impacts and earthquakes, can occur and that they are ordinary geological processes.
\end{abstract}

Since the 17th century geologists in Europe and Britain, and later North America found that they could determine the relative ages of rock successions and could compare the rock successions over long distances, by applying stratigraphic 
principles. The result of this research was the geological timescale, as well as a description of the broad history of life on earth. This geological timescale was already completed at the end of the 1830s. This completion happened more or less 55 years before the publication of Darwin's theory of evolution by natural selection in 1895. By using radiometric dating, it became possible to assign absolute ages to the different Periods of the geological timescale. That provided a good test for the reliability of the principles applied when the timescale was compiled. Nowhere were any contradictions found between the relative ages of Periods in the timescale and their absolute ages. The geological timescale is not invalidated by limitations in the application of radiometric dating, because the timescale is based on relative age and fossil content.

The concept of deep space is readily accepted by Christians, but not the concept of deep time. It is important to remember that deep space and deep time are scientific concepts; findings, theories and concepts that may change when new knowledge is gained. Our faith, however, is not subject to scientific theories. We steadfastly stand by what we know and believe: God is the Creator and Sustainer of everything - of the whole universe. Scientific findings serve to bring us a deeper awareness of God's omnipotence.

\section{Opsomming}

\section{Kontekstualisering: geologiese tydskaal en preservering van die fossielrekord}

Ons gaan van die standpunt uit dat die heelal as gevolg van 'n oerknal, 13000 miljoen jaar gelede, ontstaan het. Die aarde het 4600 miljoen jaar gelede in die bekende galaktiese stelsel gevorm. Die konsep van geologiese tyd en die meting daarvan het met verloop van die geskiedenis van die mens verander. Sommige natuurwetenskaplikes het tydens die agtiende eeu onder die indruk gekom van 'n baie ou aarde, hoewel dit nie moontlik was om die absolute ouderdom van die aarde te bepaal voor die ontdekking van radioaktiwiteit (1896) en die toepassing daarvan in die datering van rotse (1905) nie. James Hutton (1726-1797) se beginsel van uniformiteit ("the present is the key to the past") word in die moderne geologie eerder vervang met die konstantheid van die natuurwette en uniforme prosesse. Daar word egter erken dat die tempo van prosesse aansienlik kan varieer en dat natuurlike katastrofiese gebeure, byvoorbeeld meteorietimpakte en aardbewings, wel voorkom en dat dit gewone geologiese prosesse is.

Sedert die sewentiende eeu het geoloë in Europa en Brittanje en later ook Noord-Amerika gevind dat hulle met behulp van 
stratigrafiese beginsels, die relatiewe ouderdomme van gesteente-opeenvolgings kon bepaal en gesteente-opeenvolgings oor groot afstande met mekaar kon vergelyk. Die resultaat van hierdie navorsing is die geologiese tydskaal wat reeds teen die einde van die tagtigerjare voltooi is en daarmee saam ook 'n beskrywing van die breë geskiedenis van lewe op aarde. Dit was ongeveer 55 jaar voordat Darwin se teorie van evolusie deur natuurlike seleksie in 1895 gepubliseer is. Met behulp van radiometriese datering het dit moontlik geword om absolute ouderdomme toe te ken aan die verskillende Periodes van die geologiese tydskaal. Dit was 'n goeie toets vir die betroubaarheid van die beginsels waarvolgens die tydskaal saamgestel is. Teenstrydighede tussen die relatiewe en absolute ouderdomme van Periodes in die tydskaal is nêrens gevind nie. Beperkings in die toepassings van radiometriese daterings word erken, maar dit maak nie die geologiese tydskaal ongeldig nie, want die tydskaal is gebaseer op relatiewe ouderdom en fossielinhoud.

Die konsep van "deep space" is geredelik deur Christene aanvaar, maar nie dié van "deep time" nie. Dit is belangrik om te onthou dat "deep space" en "deep time" wetenskaplike konsepte is; bevindings, teorieë en begrippe wat kan verander namate nuwe kennis ingewin word. Ons geloof is egter nie ondergeskik aan wetenskaplike teorieë nie. Ons staan vas in dit wat ons weet ons glo: God is die Skepper en Onderhouer van alles, die hele heelal. Wetenskaplike bevindings bring 'n mens dieper onder die indruk van God se almag.

\section{Inleiding}

Aschman (1984) maak die volgende stelling (in Afrikaans weergegee):

Wanneer die heelal beskou word, word veronderstel dat daar ' $n$ aanvangstoestand was en wette wat daarop ingewerk het, wat aanleiding gegee het tot die ontstaan van die vroeë heelal. Deur die werking van die fisikawette wat vandag aan ons bekend is, het die moderne heelal tot stand gekom.

Aan die PUK gee die navorsers egter 'n tree verder terug en gaan van die veronderstelling uit dat God reeds voor die aanvangstoestand daar was en dat Hy die Inisieërder van die vormende wette is wat op die heelal ingewerk het en steeds inwerk.

Die outeurs aanvaar dat die vroeë wette dieselfde wette is wat ons vandag waarneem. Ter stawing van hierdie stelling word verwys na die natuurlike ${ }^{235} \mathrm{U}$-fossielreaktor in Gaboen. ' $n$ Analise van die data 
wat in verband met hierdie "fossielreaktor" ingewin is, toon dat dieselfde wette van fisika reeds $4.5 \times 10^{9}$ jaar gelede gegeld het.

In hierdie artikel word van die veronderstelling uitgegaan dat 'n oerknal die oorsprong van die heelal was. Die geskiedenis begin by tyd $t=0$; binne die eerste $t=10^{-35}$ sekonde ontstaan die eerste kwarke; op $t=4$ minute begin kernsintese en ongeveer 'n miljoen jaar later, begin materie die heelal oorheers. Tans word die ouderdom van die heelal bereken op $t=1.3 \times 10^{10}$ jaar. Die aarde, in sy eie sonnestelsel, het uit die newelwolk van deeltjies gekondenseer, inkrimping ondergaan en 'n plat skyf gevorm wat om 'n middelpunt begin roteer het. Ongeveer op tyd $t=0.4 \times 10^{10}$ jaar het die aarde in die bekende galaktiese stelsel gevorm. Die vroeë aarde het waarskynlik 'n uniforme samestelling en digtheid gehad, maar met aardverwarming (die effek van botsende deeltjies, swaartekrag en radioaktiewe verval) is die aarde omvorm tot 'n kern met hoë digtheid (Fe-Ni-samestelling) en 'n kors met laer digtheid (silikate). Dit het dan tot die gedifferensieerde aarde gelei waarop tipiese geologiese prosesse kon plaasvind.

Die oerknalteorie bring ' $n$ mens te staan voor 'n tydsbegrip van ' $n$ heelal wat $1.3 \times 10^{10}$ jaar oud kan wees - 'n tydsbegrip wat ons verstand te bowe gaan. Dit is moeilik om die verloop van soveel jare te visualiseer in vergelyking met die mens se lewenspan van ongeveer 70 tot 100 jaar.

\section{Geologiese tyd en die geologiese tydskaal}

Deur die loop van die menslike geskiedenis het die ontwikkeling van die konsep van geologiese tyd en die meting daarvan verander. Hierdie idee van geologiese tyd is die grootste bydrae wat geologie tot die algemene denke gelewer het. Dit was net so rewolusionêr soos die besef van die uitgestrektheid van die heelal en die verband tussen materie en energie (Doyle et al., 2001).

Voor die ontdekking van radioaktiwiteit (1896) is verskeie pogings aangewend om die ouderdom van die aarde te bereken. Die natuurwetenskaplikes was bewus van die hoë ouderdom van die aarde. Die Skotse geoloog James Hutton (1726-1797) het byvoorbeeld deur waarneming van blootgestelde gesteentes en geologiese prosesse besef dat die aarde baie, baie oud moet wees. In Tabel 1 is voorbeelde van die pogings wat aangewend is om die ouderdom van die aarde te bepaal. 
Tabel 1: Pogings wat aangewend is om die ouderdom van die aarde te bepaal voor die toepassing van radiometriese datering, asook van die eerste ouderdomme wat met behulp van radiometriese daterings verkry is (oorgeneem uit Dalrymple, 1991). (mj - 1 miljoen jaar)

\begin{tabular}{|c|c|c|c|}
\hline Gebaseer op: & Outeur & $\begin{array}{l}\text { Wanneer } \\
\text { bereken }\end{array}$ & $\begin{array}{l}\text { Ouderdom } \\
\text { van aarde } \\
\text { (jaar) }\end{array}$ \\
\hline \multicolumn{4}{|l|}{ RELIGIE } \\
\hline Hindoe-chronologie & Priesters & $120-150$ v.C. & 2000 mj \\
\hline Bybelse chronologie & Theophilus van Antiogië & 169 n.C. & 7519 \\
\hline Bybelse chronologie & Eusebius van Sesarea & 4de eeu & 7167 \\
\hline Bybelse chronologie & St. Basil die Grote & 4de eeu & 5994 \\
\hline Bybelse chronologie & St. Augustine & 5 de eeu & 6321 \\
\hline Bybelse chronologie & Alfonso X & 13de eeu & 8952 \\
\hline Bybelse chronologie & Pico della Mirandola & $\sim 1490$ & 5471 \\
\hline Bybelse chronologie & John Lightfoot & 1644 & 5918 \\
\hline Bybelse chronologie & James Ussher & 1650 & 5994 \\
\hline \multicolumn{4}{|c|}{ TEMPERATUUR (aanname: die aarde was oorspronklik in gesmelte toestand) } \\
\hline Afkoeling van die aarde & Comte de Buffon & 1774 & 75000 \\
\hline Afkoeling van die aarde & Lord Kelvin & 1862 & $20-400 \mathrm{mj}$ \\
\hline Afkoeling van die aarde & S. Haughton & 1865 & $>1280 \mathrm{mj}$ \\
\hline Afkoeling van die aarde & Lord Kelvin & 1871 & $<100 \mathrm{mj}$ \\
\hline \multicolumn{4}{|c|}{ VERSAMELING VAN SEDIMENTE OP DIE AARDE SE OPPERVLAK } \\
\hline & A. Holmes & 1913 & $250-350 \mathrm{mj}$ \\
\hline & J. Barrel & 1917 & $1250-1700 \mathrm{mj}$ \\
\hline \multicolumn{4}{|l|}{ RADIOAKTIWITEIT } \\
\hline Verval van $\mathrm{U}$ en $\mathrm{Pb}$ in kors & H.N. Russell & 1921 & $2000-8000 \mathrm{mj}$ \\
\hline Verval van $\mathrm{U}$ en $\mathrm{Pb}$ in kors & A. Holmes & 1927 & $1600-3000 \mathrm{mj}$ \\
\hline Verval van $\mathrm{U}$ en $\mathrm{Pb}$ in kors & E. Rutherford & 1929 & $3400 \mathrm{mj}$ \\
\hline Verval van $\mathrm{U}$ en $\mathrm{Pb}$ in kors & S. Meyer & 1937 & $4600 \mathrm{mj}$ \\
\hline $\begin{array}{l}\text { Verval van } \mathrm{U} \text {, Th en } \mathrm{Pb} \text { in } \\
\text { kors en minerale }\end{array}$ & A. Holmes & 1931 & $1600-3000 \mathrm{mj}$ \\
\hline $\mathrm{Pb}$-isotope in aarde & E.K. Gerling & 1942 & $3940 \mathrm{mj}$ \\
\hline $\mathrm{Pb}$-isotope in aarde & H. Jeffreys & 1948 & $1340 \mathrm{mj}$ \\
\hline Verval van K-isotope na Ca & A.K. Brewer & 1937 & $<3000 \mathrm{mj}$ \\
\hline Verval van $\mathrm{Rb}$-isotope na $\mathrm{Sr}$ & A.K. Brewer & 1938 & $<15000 \mathrm{mj}$ \\
\hline $\begin{array}{l}\text { Volopheid van radio- } \\
\text { aktiewe isotope }\end{array}$ & H.E. Suess & 1949 & $4000-5000 \mathrm{mj}$ \\
\hline
\end{tabular}


Om 'n gevoel te kry van die tempo waarteen verskillende geologiese prosesse en gebeure plaasgevind het en tans nog plaasvind, kan die volgende "skaal" (Tabel 2) gebruik word (Press \& Siever, 1998).

Tabel 2: Die tempo waarteen sommige van die algemene geologiese prosesse en gebeure plaasvind. (Let op dat die skaal logaritmies is.)

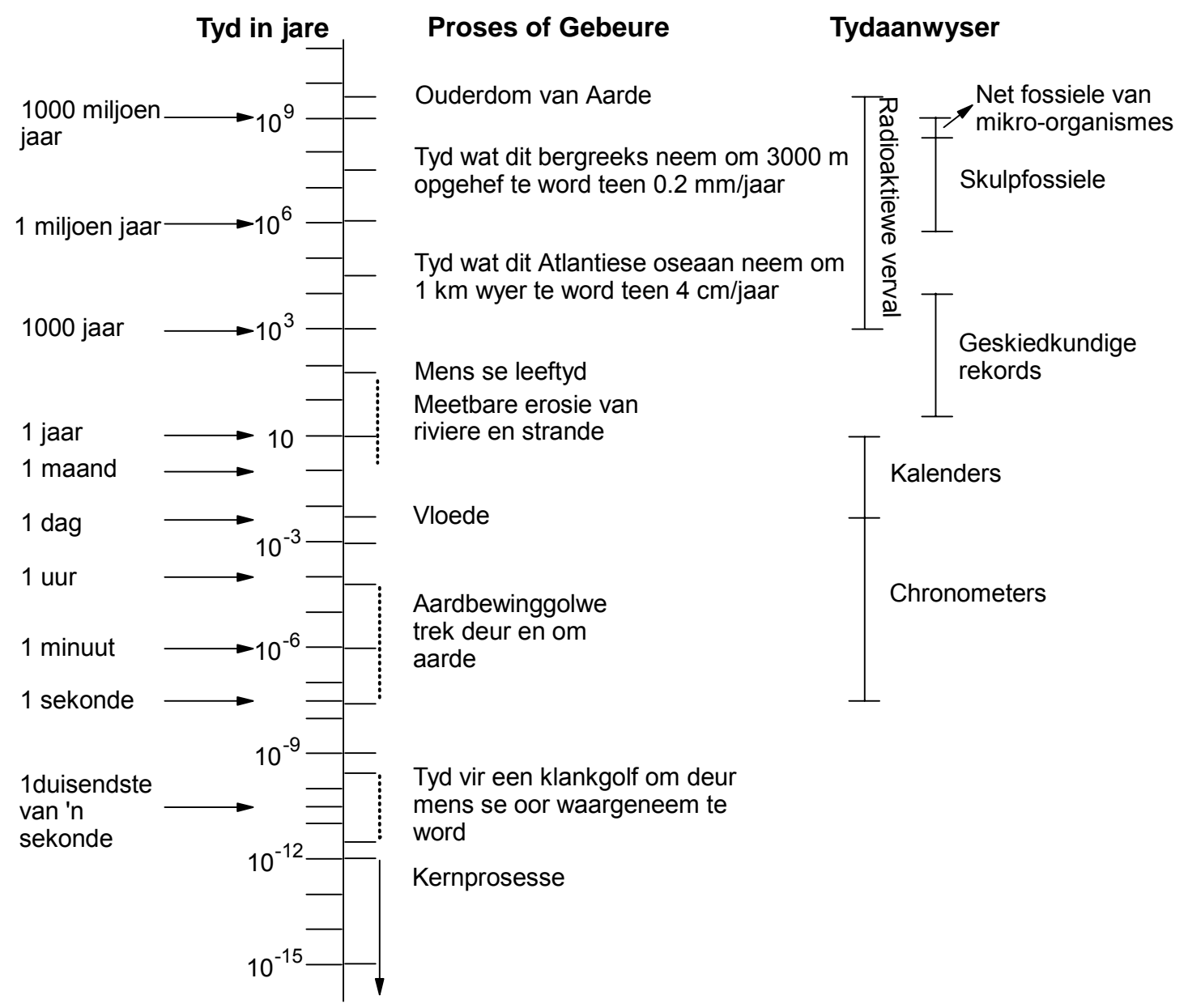

James Hutton het onder die indruk gekom van die tempo waarteen geologiese prosesse verloop en het besef dat die aarde baie oud moet wees om deur die waargenome prosesse tot die huidige toestand gevorm te kon word. Hy het die beginsel van uniformiteit geformuleer, wat populêr gestel kan word as dat "the present is the key to the past". In die moderne geologie word verkieslik van die beginsel van aktualiteit gepraat:

Actualism only assumes the uniformity of processes; that is: that the laws of nature have been constant through time. Modern geology recognises that the rates at which processes 
have operated have varied greatly, and that natural catastrophic events do occur and may be preferentially recorded in the stratigraphic record (Doyle et al., 2001).

'n Behoefte het ontstaan om gesteentelae in 'n chronologiese volgorde te plaas, sodat opeenvolgings van gesteentelae van verskillende geografiese gebiede met mekaar vergelyk kan word, ter wille van prospekteringsdoeleindes. William Smith (1769-1839) het bevind dat lae van verskillende gebiede in Brittanje met mekaar vergelyk kan word met behulp van die fossielinhoud daarvan. Smith het naamlik waargeneem dat "populations of organisms always change through time and once changed will not appear again in their previous form" (Ojakangas \& Darby, 1976). Die geoloë van die agtiende en negentiende eeu het gebruik gemaak van relatiewe datering om vas te stel watter lae ouer en watter lae jonger as 'n bepaalde laag sou wees. Dit is eers met die ontdekking van radioaktiwiteit in 1896 en die toepassing daarvan in die datering van gesteentes (voorgestel deur Rutherford in 1905), dat dit vir geoloë moontlik was om absolute ouderdomme aan gesteentes toe te ken.

Die relatiewe datering van gesteentes berus op die volgende sewe fundamentele beginsels:

- Superposisie van lae. (Die oudste laag onder en die jongste laag bo in onversteurde sedimentêre lae.)

- Oorspronklike horisontaliteit. (Sedimentêre lae word oorspronklik horisontaal afgeset.)

- Laterale kontinuïteit. ('n Sedimentêre laag word sydelings aaneenlopend afgeset tot teen die rand van die afsettingskom.)

- Dwarssnydende verhoudings. (Waar gange van stollingsgesteentes deur gelaagde gesteentes sny, of waar gesteentelae verskuif is, sal die gang/verskuiwing die jongste wees.)

- Waar brokstukke (insluitsels) van ouer gesteentes deur jonger gesteentes ingesluit word. (Alleen as 'n gesteente reeds bestaan het, kan dit ingesluit word in 'n ander, jonger gesteente.)

- Nêrens op aarde bestaan 'n volledige, ononderbroke rekord van al die gesteentes wat op die aarde gevorm het nie, want periodes van nie-afsetting en erosie veroorsaak gapings in die gesteenterekord. Periodes van nie-afsetting kan nie waargeneem word nie, maar wel erosie-oppervlakke, wat diskordansies genoem word. Diskordansies is handig in die identifisering van 'n periode van erosie. 
Sedert die sewentiende eeu maak wetenskaplikes gebruik van hierdie eenvoudige metodes van relatiewe datering om gesteentes te klassifiseer as relatief ouer of jonger. Hierdie metodes kan egter nie gebruik word om die relatiewe ouderdom van lae oor groot afstande te vergelyk nie, want daar is gewoonlik nie laterale kontinuïteit nie.

Deur fyn waarneming het William Smith besef dat fossiele nie willekeurig deur die aarde se geskiedenis voorkom nie, maar in 'n standhoudende volgorde op 'n regionale en selfs wêreldwye skaal. Oraloor gaan marine invertebrate die eerste visse vooraf; die eerste spoordraende plante (soos varings) verskyn vroeër as die blomdraende plante. Verder verskyn en verdwyn individuele spesies in 'n soortgelyke konstante volgorde in groter families van spesies. Fossiele is meer uniek as gesteentesoorte en baie meer gevarieerd. Sodoende is die potensiaal vir die onderverdeling van gesteentelae met behulp van fossielinhoud, baie groter as bloot net relatiewe datering.

Teen die einde van die tagtigerjare is die meeste van die geologiese Periodes vanaf die Kambrium (kyk Tabel 3) en jonger vasgestel volgens hul fossielinhoud en relatiewe posisies in die stratigrafie. Die breë geskiedenis van lewe op aarde was dus toe reeds goed beskryf. Die geologiese tydskaal verteenwoordig die "volledige" rekord van die gesteentes wat tydens die aarde se geskiedenis gevorm het. Deur korrelasie van die gesteenterekords van verskillende dele van die aarde, was dit moontlik om onvolledige rekords aan te vul, want as erosie op een plek voorkom, vind afsetting elders plaas.

Die fossielopeenvolging is deeglik en onafhanklik vasgestel lank voor Darwin se teorie van evolusie deur natuurlike seleksie in 1859 gepubliseer is. Fossielopeenvolging en die geologiese tydskaal (Tabel 3) is afhanklik van geologiese waarnemings, en nie van die evolusieteorie nie. Die indeling van die geologiese tydskaal in tydeenhede, is gebaseer op massa-uitsterwings, soos verteenwoordig in die fossielrekord of die kortstondige geologiese gebeure (byvoorbeeld vulkaniese uitbarstings) wat wêreldwyd voorgekom het. 
Tabel 3: Die geologiese tydskaal soos saamgestel in die vroeë negentiende eeu. Die ouderdomme van die grense tussen Periodes is eers in die twintigste eeu bygevoeg. Die linkerkanste kolom verwys na 'n paar prominente geologiese en biologiese gebeure (Monroe \& Wicander, 2001).

\begin{tabular}{|c|c|c|c|c|}
\hline $\begin{array}{l}\text { Hoof geologiese en } \\
\text { biologiese gebeure }\end{array}$ & $\begin{array}{l}\text { Ouderdomme } \\
\times 10^{6} \text { jaar } \\
\text { gelede }\end{array}$ & Periode & Era & Eon \\
\hline & \multirow{2}{*}{1.6} & Kwaternêr & \multirow[t]{2}{*}{ Senosoïkum } & $\mathrm{F}$ \\
\hline Vroegste mense & & Tersiêr & & A \\
\hline $\begin{array}{l}\text { Uitsterwing van } \\
\text { dinosourusse }\end{array}$ & 66 & Kryt & Mesosoïkum & $\mathrm{N}$ \\
\hline Eerste voëls & 144 & Jura & & $F$ \\
\hline $\begin{array}{l}\text { Eerste soogdiere } \\
\text { Eerste dinosourusse }\end{array}$ & 208 & Trias & & $\mathrm{R}$ \\
\hline $\begin{array}{l}\text { Ontstaan van oer- } \\
\text { kontinent Pangea }\end{array}$ & 245 & Perm & & $\mathrm{O}$ \\
\hline $\begin{array}{l}\text { Steenkoolvormende } \\
\text { moerasse } \\
\text { Eerste reptiele }\end{array}$ & 286 & Karboon & & $S$ \\
\hline \multirow[t]{2}{*}{ Eerste amfibieë } & 360 & Devoon & Paleosoïkum & $\mathrm{O}$ \\
\hline & 408 & Siluur & & Ï \\
\hline $\begin{array}{l}\text { Eerste landplante } \\
\text { Eerste visse }\end{array}$ & 438 & Ordovisium & & $U$ \\
\hline Vroegste skulpdiere & 545 & Kambrium & & $\mathrm{M}$ \\
\hline \multirow{3}{*}{$\begin{array}{l}\text { Eerste fossielrekord } \\
\text { van lewe: eensellige } \\
\text { organismes }\end{array}$} & 2500 & & Proterosoïkum & \multirow{3}{*}{$\begin{array}{l}\text { VOOR- } \\
\text { KAM- } \\
\text { BRIUM }\end{array}$} \\
\hline & \multirow[t]{2}{*}{4000} & & Argeïkum & \\
\hline & & & Hadeaan $\underline{s}$ & \\
\hline
\end{tabular}


Daar was egter steeds 'n behoefte by natuurwetenskaplikes om die ouderdom van die aarde in jare uit te druk. Uiteindelik is met die ontdekking en toepassing van radioaktiwiteit 'n aanvaarbare metode ontwikkel, naamlik radiometriese datering.

\section{Radiometriese datering}

Lord Kelvin het in 1872 en 1876 die aarde se ouderdom bereken, gebaseer op studies van hittevloei in die aarde (Tabel 1). Kelvin het die toename in temperatuur met diepte in die aardkors in verband gebring, met die aanname dat die hitte die produk is van 'n aarde wat steeds afkoel, nadat dit aanvanklik in 'n gesmelte toestand was. Sy berekenings het aangedui dat die aarde niks ouer as 400 miljoen jaar en niks jonger as 20 miljoen jaar kan wees nie. Kelvin se berekenings het geoloë ontsenu, want hulle het besef dat selfs 400 miljoen jaar 'n té kort tydperk is (Ojakangas \& Darby, 1976). Met die ontdekking van radioaktiwiteit, is die dilemma waarmee Kelvin die geoloë gelaat het, opgelos. Daar is naamlik 'n interne hittebron, wat deurlopend "nuwe" hitte-energie genereer uit die hitte wat opgewek word deur die radioaktiewe verval van isotope, soos $\mathrm{U}^{238}$ en $\mathrm{K}^{40}$. Rutherford het in 1905 daarop gewys dat gesteentes fisies gedateer kan word deur die hoeveelhede van 'n radioaktiewe isotoop en die ooreenstemmende vervalproduk te meet. Indien die vervalkonstante van die radioaktiewe isotoop bekend is, kan die ouderdom bereken word (Monroe \& Wicander, 2001).

Die volgende beperkings moet egter in ag geneem word:

- Sedimentêre gesteentes kan nie gedateer word nie, want dit bestaan uit minerale wat van reeds bestaande gesteentes verkry is, en sal dus 'n té hoë ouderdom gee.

- Waar die radioaktiewe vervalproduk 'n gas is, kan van die gas "uitlek", wat aanleiding gee tot 'n té jong ouderdom.

- Daar moet seker gemaak word dat met 'n geslote sisteem gewerk word. Geen verwydering (loging) of toevoeging van materiaal tot die gesteente moes dus plaasgevind het nie. Loging van die vervalproduk gee aanleiding tot 'n té jong ouderdom, terwyl toevoeging van die vervalproduk 'n té hoë ouderdom sal gee.

- Die proses van metamorfisme gee aanleiding tot die herverspreiding van die vervalproduk; die ouderdom van die metamorfe proses word dan bepaal, en nie dié van die oorspronklike gesteente nie. Die geologiese klok van daardie 
gesteente word dus as gevolg van metamorfose na nul teruggestel.

Hierdie beperkings kan oorkom word deur:

- onverweerde, onveranderde gesteentes te gebruik;

- gebruik te maak van meer as een isotooppaar ('n radioaktiewe element en sy vervalproduk), wat ooreenstemmende ouderdomme moet gee; en

- verbeterde tegnieke en analitiese instrumente, wat die akkuraatheid van bepalings verhoog. Akkurater ouderdomme met kleiner foutgrense $(0,5$ tot $0,1 \%$ van die ouderdom) word dus deesdae bepaal $(0,5 \%$ van 3500 miljoen jaar is $\pm 17,5$ miljoen; $0,1 \%$ van 3500 miljoen jaar is $\pm 3,5$ miljoen).

- Uit hierdie radiometriese bepalings is die oudste gesteentes wat tot dusver op aarde ontdek is, die volgende:

- Sirkoonminerale uit sediment in Australië (4,2 × $10^{9}$ jaar oud).

- Die oudste gesteentes is die Acastagneis in Kanada $\left(4,0 \times 10^{9}\right.$ jaar oud).

- Die oudste kontinentkors is in Groenland (3,8 $\times 10^{9}$ jaar oud).

- In Suid-Afrika is die oudste groenstene dié met 'n ouderdom van $3,6 \times 10^{9}$ jaar.

\section{Samevatting}

Die konsep van geologiese tyd is veral van belang vir biologiese ontwikkeling. Dit is insiggewend dat die geologiese tydskaal (saamgestel teen die einde van die 1830's), wat gebaseer is op die relatiewe ouderdomme tussen gesteentelae en die fossielrekord, bitter min veranderings ondergaan het sedert die gebruik van radiometriese datering (vanaf ongeveer 1905). Met die verfyning van metingsprosedures en verbeterde analitiese instrumente, is daar weinig verandering in die ouderdomme soos bepaal in die twintigste eeu.

Die konsep van 'n aansienlik uitgebreide heelal en die sogenaamde deep space is geredelik deur Christengelowiges aanvaar, maar nie dié van 'n oeroue aarde of deep time nie. Dit is nodig dat 'n mens besef dat die konsepte van geologiese tyd en geologiese tydskaal 
deel is van hipoteses en teorieë en dat dit op wetenskaplike vlak lê. Enige konsep, hipotese en teorie kan en moet verander of aangepas word namate nuwe kennis ingewin en nuwe ontdekkings gemaak word. Op hierdie (wetenskaplike) vlak behoort dit geen verskil te maak aan ons geloof nie. God bly steeds die Skepper en Onderhouer. Ons stel dit dat die Genesisrekord van die skeppingsdae as tydperke met ongedefinieerde tydsverloop gesien word en uitgedruk is in die verwysingsraamwerk van die skrywer van Genesis. Merkwaardig is die breë ooreenkoms tussen die skeppingsdae en die fossielrekord: skeiding van land en see, die skepping van plante, gevolg deur dié van visse en diere en laaste die mens. 'n Baie ou aarde van 4600 miljoen jaar maak nie die skeppingsverhaal, soos opgeteken in Genesis, irrelevant of ongeldig nie. Saam gesien, behoort dit ons onder die indruk te bring van God se almag.

\section{Geraadpleegde bronne}

ASCHMAN, D. 1984. The physics of the early universe. SAIP Winter School, University of Cape Town, July 1984. Cape Town: University of Cape Town.

DALRYMPLE, G.B. 1991. The age of the earth. Stanford: Stanford University Press.

DOYLE, P., BENNETT, M.R. \& BAXTER, A.N. 2001. The key to earth history: an introduction to stratigraphy. 2nd ed. New York: Wiley.

MONROE, J.S. \& WICANDER, R. 2001. The changing earth. 3rd ed. New York: Brooks/Cole.

OJAKANGAS, R.W. \& DARBY, D.G. 1976. The earth past \& present. New York: McGraw-Hill.

PRESS, F. \& SIEVER, R. 1998. Understanding earth. 2nd ed. New York: Freeman.

Kernbegrippe:

fossielrekord

geologiese tydskaal

konsep van tyd

radiometriese datering

Key concepts:

concept of time

fossil record

geological timescale

radiometric dating 